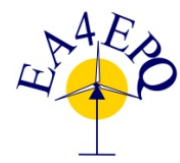

International Conference on Renewable Energies and Power Quality (ICREPQ'17)

Malaga (Spain), $4^{\text {th }}$ to $6^{\text {th }}$ April, 2017

Renewable Energy and $\mathscr{P}_{\text {ower }}$ Quality Gownal (RE\&PQJ)

ISSN 2172-038 X, No.15 April 2017

\title{
Study on Voltage Control of Distribution Network Using PV Generation Forecasting
}

\author{
H. Kobayashi ${ }^{1,2}$ and M. Kato ${ }^{2}$ \\ ${ }^{1}$ Polytechnic University, 2-32-1 Ogawa-nishimachi, Kodaira-shi, Tokyo, 187-0035, (Japan) \\ Phone number: +81 42346 7491, e-mail: kobayashi@uitec.ac.jp \\ ${ }^{2}$ Department of Electrical and Electronic Engineering, Tokyo Denki University \\ 5 Senju asahi, Adachi, Tokyo, 120-8551, (Japan)
}

\begin{abstract}
With the expected spread of photovoltaic (PV) systems, high power generation in spring and summer is expected to cause abnormally high voltage in distribution systems. As described in herein, we propose a method to improve the utilization efficiency of a small-scale PV generator connected to a distribution system by short-term $(30 \mathrm{~min})$ forecasting of solar power generation output in a small area of a few kilometers. As a countermeasure against abnormally high voltage, a method exists to adjust the voltage by switching a tap of the substation transformer. However, the switching frequency of the tap with mechanical contact is limited to once or twice per hour. Under these conditions, if short-term forecasting of solar power generation were possible, then tap changing of a substation transformer efficiently could maintain voltage within an appropriate range, which enables effective use of solar power. This paper is organized as follows. After a short-term forecast method of solar power is proposed. The method of adjusting the sending end voltage of a distribution substation based on the PV output forecast data is proposed. Finally, reduction of the PV disconnection frequency is verified numerically.
\end{abstract}

\section{Key words}

forecast, disconnection, distribution line, smoothing effect.

\section{Introduction}

Solar power generating systems provide renewable energy, but they have the shortcoming of providing little power generation per unit of area. In Japan, because of a nuclear accident caused by the 2011 earthquake and tsunami, interest in renewable energy is increasing, especially in photovoltaic (PV) power generation. However, Japan has few flat areas. The spread of so-called mega-solar projects is constrained by the scarcity of useful land.

Generally, PV arrays installed on residential rooftops are of small scale, less than $10 \mathrm{~kW}$, but most are about 3-5 $\mathrm{kW}$. The daily electricity usage of a typical Japanese house is $20-25 \mathrm{kWh}$, depending on the roof size, the electricity demand during the day, the installation cost, etc. Surplus electricity generated during the day can be sold through PCS and the distribution grid, but these arrays are not intended to provide electricity to a wide area administered by electric power companies. Still the arrays can assist in augmenting the electricity supply to residential areas. In Japan, for reasons of network protection, distribution lines from the substation are connected radially: surplus power must be consumed within the same power distribution line.

For these reasons, the power generated in the distribution system is assumed to be consumed within the distribution system. However, considering the characteristic that PV power generation fluctuates even during the day and does not generate electricity at night, the power supply from the power utility remains indispensable. Although the use of a power storage device (storage battery, etc.) is effective [1], at present, it is not popular in terms of price, installation location, safety assurance, etc.

Generally in Japan, three-phase $6,600 \mathrm{~V}$ is supplied to each node over lines extending several kilometers. Voltage is changed to $202 \pm 20 \mathrm{~V}$ and $101 \pm 6 \mathrm{~V}$ by pole transformers. The voltage on the distribution line must be adjusted in consideration of the whole voltage balance because of the electric resistance of the distribution line. Because of such circumstances, changes in system power demand and changes in PV generation tend to cause large changes in voltage, particularly at the ends of distribution lines.

On rainy or cloudy days, the distribution system receives most of the demanded electricity from electric power companies. In such situations, if the PV-generated power increases rapidly, the voltage rises, causing a risk of deviating from the specified value. As a countermeasure, a Power Conditioning System (PCS) temporarily reduces the output power or disconnects it using a voltage monitoring function, thereby keeping the voltage within the specified value. As a result, solar power is used ineffectively.

Over the long term, a pole transformer tap can adjust the voltage. In the short term, it can be adjusted by switching a tap of the substation transformer. However, the PV power is affected strongly by the weather: the generated power changes drastically within several minutes. Therefore, the mechanical tap change method cannot be used. The system is forced to disconnect the PV system.

Conventional solar radiation forecasting is often used as a method for power utilities to obtain maximum electric power and maximum profit in operations using large-scale photovoltaic power generation [2]-[15]. In the case of so- 
called mega-solar and large-scale PV systems, the effects of local cloud motion can be reduced by smoothing [16] [20]. Forecasting information is effective for methods using wide area weather forecasting or meteorological satellites. However, they have remained unsuitable for application to distribution systems in the range of several kilometers. Adjustment of the feed voltage from the substation could be run efficiently, and the probability of PV disconnection could be reduced, if PV power generation forecasting of several tens of minutes ahead were possible.

This paper proposes a short-term forecasting method, describes application of the forecasted results to a distribution system, and presents verification of the results.

\section{Forecasting Method of Solar Irradiation and PV Generation}

PV generation forecasting methods have been variously proposed. This study examines stabilization of a distribution system's voltage to increase PV power generation efficiency. To do so, it is necessary to forecast the temporal change of solar irradiance value and PV power generation value in a target area. The length of one power distribution system is several kilometers. The switching frequency of the tap of a substation is about once or twice per hour.

The conditions necessary for forecast in this study are as follows.

$<$ Condition $1>$ The target area is narrow.

$<$ Condition $2>$ The forecasted time is short.

$<$ Condition $3>$ The forecasted data must be sufficient to calculate the PV generation value [21]

Forecasting methods proposed in earlier reports use a numerical weather model for weather forecasting, meteorological observation data applied for solar radiation forecasting, solar radiation forecasting using cloud image data observed from the ground, and solar radiation forecasting using satellite images [22]-[24], or a combination of these methods.

The method using a numerical model for weather and the method using satellite images are useful for wide areas, with forecasted time as long as several hours to several days. Cloud images observed from the ground are useful for a radius several kilometers, with forecasting time of several minutes to about $15 \mathrm{~min}$. The method is useful for forecasting on a local system scale. However, special equipment installation and image processing are required.

PV generation forecasting methods have been variously proposed. Our study applies a method using the amount of PV generation or solar irradiance in a nearby area. The solar radiation intensities of the near multipoint distribution system are measured. Then short-term forecasts are made through inference from correlation. A strong positive correlation is known to exist between solar irradiance and PV generation. The solar radiation intensity depends on weather conditions at each point. Solar radiation intensity is greatly affected by cloud movement. In general, clouds move while changing shape. Therefore, time-series data at each observation point tend to present mutually similar waveforms at different times. By analyzing nearby solar radiation irradiance information and considering of movement speed and direction of clouds, one can forecast the short-term solar radiation intensity of a given location.

Smart meter systems, which automatically collect grid data, are becoming more common with automated meter reading systems, and are expected to become increasingly popular. In this study, PV power generation data of five measurement points were used as presented in Fig. 1. Fig. 2 shows the measurement equipment using PV.

As shown in Fig. 3, to approximate the solar radiation irradiance at two points, a cut-out of the time series data in the time zone window is done first. Then, correlation coefficients of other time-series data are calculated while moving the time axis of the series data [25].

By determining the time difference at which the correlation is the strongest, the cloud movement time can be estimated. From movement of the clouds measured at multiple points, the moving directions and moving distance are estimated. Then the time series of solar radiation intensity at the forecasting point can be estimated. Because the major cause of solar radiation irradiance can be assumed to be cloud influence, the amount of power generation at the windward point from the forecast point appears after some time lag. This time lag represents moving time of clouds.

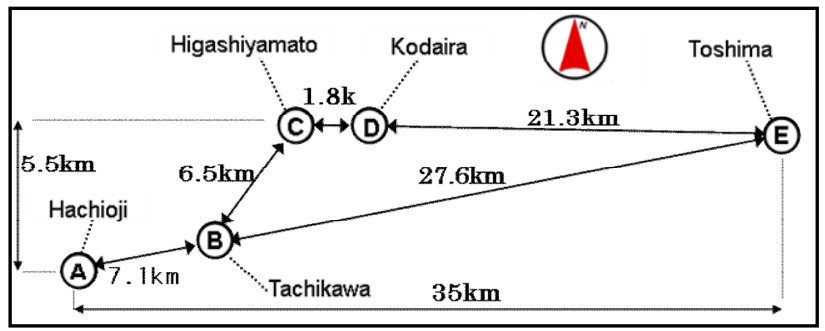

Fig. 1. Location of measuring point (Tokyo, Japan).

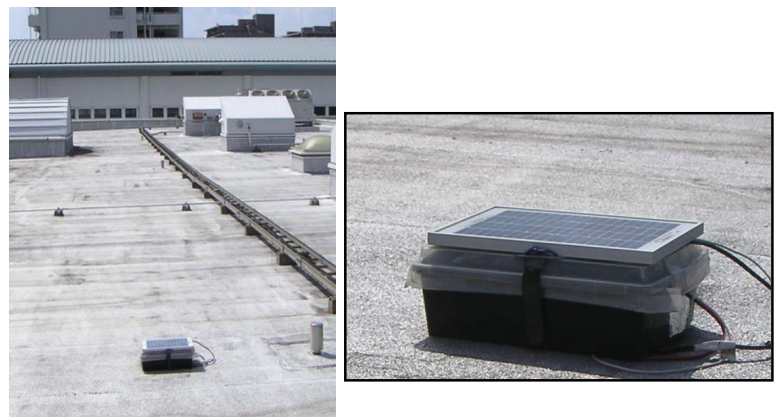

Fig. 2. Measurement Equipment using PV. 
Correlation coefficients of solar radiation irradiance obtained from multiple points includes cloud movement information. Furthermore, it is possible to forecast solar irradiance time series data using distance data between the forecast point and measured points using the following method. Solar irradiance of the forecast point is determined using equation (1). This equation uses the weighting factor on the windward data to move the time axis. The result is determined by adding them together. With movement of the time axis, using the time lag obtained using the method described previously, the weighting coefficients are determined as a function of the distance to be closer to the destination point. Fig. 4 shows the result of forecast using data of two points.

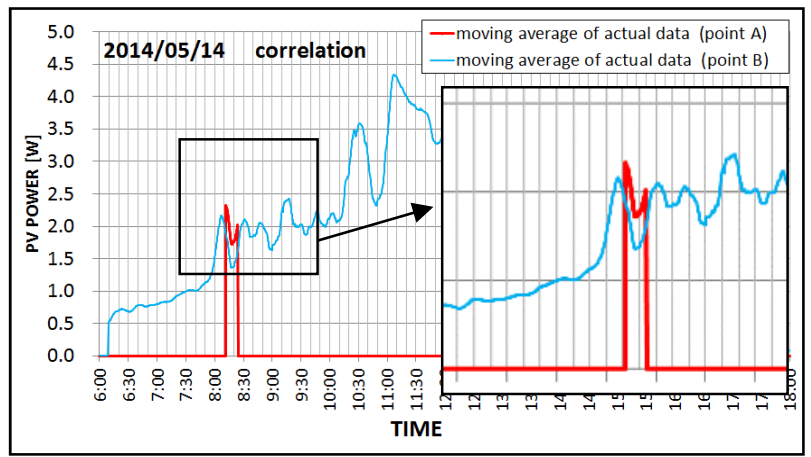

Fig. 3. Comparison of Two Point Data.

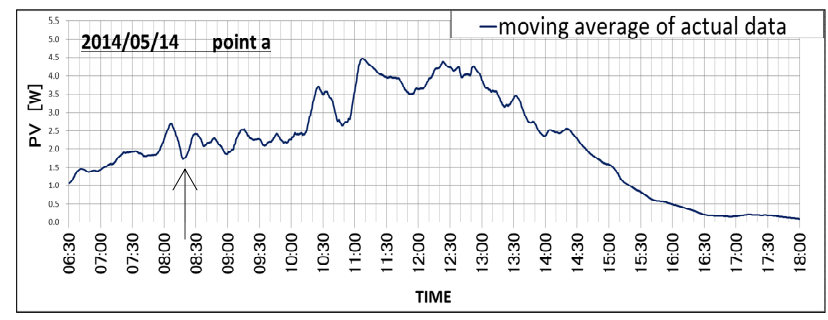

(a) Power Generation of $\mathrm{PV}$ at point $\mathrm{A}$

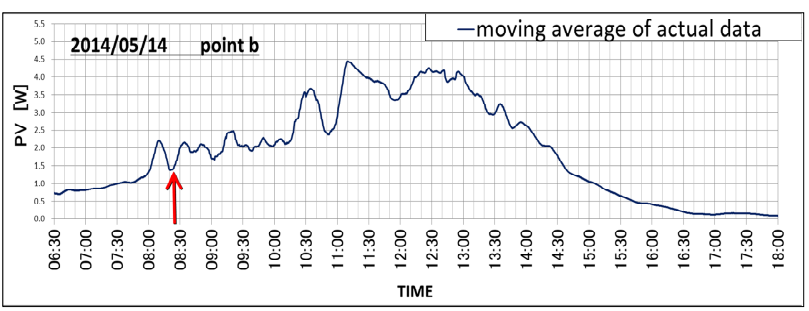

(b) Power Generation of PV at point B

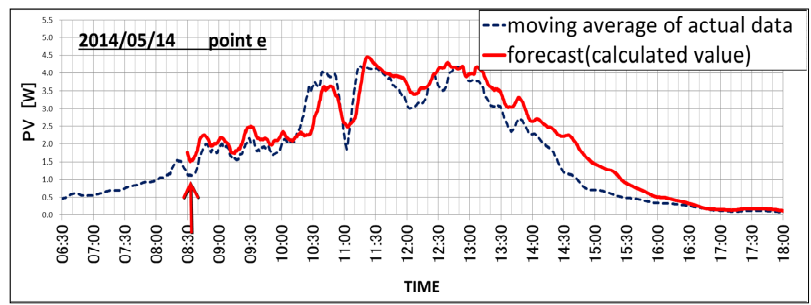

(c) Power Generation of $\mathrm{PV}$ at point $\mathrm{E}$ (actual data and forecasted data)

Fig. 4. Forecast of Power generation using two point data.

$$
P_{\mathrm{E}}(t)=K_{\mathrm{A}} P_{\mathrm{A}}\left(t+\tau_{\mathrm{AE}}\right)+K_{\mathrm{B}} P_{\mathrm{B}}\left(t+\tau_{\mathrm{BE}}\right)
$$

$P_{\mathrm{E}}(t)$ : Amount of power generated at the forecast point $\mathrm{E}$ $K_{\mathrm{A}}, K_{\mathrm{B}}$ : weighting factor at points $\mathrm{A}, \mathrm{B}$

$\tau_{\mathrm{AE}}, \tau_{\mathrm{BE}}$ : time lag between forecast point $\mathrm{E}$ and point $\mathrm{A}$ or $\mathrm{B}$

$P_{\mathrm{A}}(t)$ : power generation at time $t$ at Point A

$P_{\mathrm{B}}(t)$ : power generation at time $t$ at Point $\mathrm{B}$

Using the same method, Fig. 5 is the result of forecast using data of four points by equation (2).

$$
\begin{aligned}
P_{\mathrm{E}}(t)=K_{\mathrm{A}} P_{\mathrm{A}}\left(t+\tau_{\mathrm{AE}}\right)+K_{\mathrm{B}} P_{\mathrm{B}}\left(t+\tau_{\mathrm{BE}}\right) \\
+K_{\mathrm{C}} P_{\mathrm{C}}\left(t+\tau_{\mathrm{CE}}\right)+K_{\mathrm{D}} P_{\mathrm{D}}\left(t+\tau_{\mathrm{DE}}\right)
\end{aligned}
$$

In that equation, the following variables are used.

$K_{\mathrm{A}}, K_{\mathrm{B}}, K_{\mathrm{C}}, K_{\mathrm{D}}$ : weighting factor at point A, B, C, D

$\tau_{\mathrm{AE}}, \tau_{\mathrm{BE}}, \tau_{\mathrm{CE}}, \tau_{\mathrm{DE}}$ : time lag between the forecast point $\mathrm{E}$ and point $\mathrm{A}, \mathrm{B}, \mathrm{C}$, or $\mathrm{D}$

where $K_{\mathrm{A}}+K_{\mathrm{B}}+K_{\mathrm{C}}+K_{\mathrm{D}}=1$

$P_{\mathrm{A}}(t)$ : power generation at time $t$ at Point A

$P_{\mathrm{B}}(t)$ : power generation at time $t$ at Point $\mathrm{B}$

$P_{\mathrm{C}}(t)$ : power generation at time $t$ at Point $\mathrm{C}$

$P_{\mathrm{D}}(t)$ : power generation at time $t$ at Point D

Fig. 6 shows the error rate between the actual value and the forecasted value in two ways. In this example, in the time lag calculation, the sudden drop at 8:30 occurs only once. The same parameters are used continuously for the afternoon forecasting calculation. However, if the sequential time lag calculation is performed, the accuracy is improved.

As presented in Fig. 1, the arrangement on the map is not strictly straight, but forecasting is made using weighting coefficients according to each distance. As shown in Table 1 , the four-point method provides high accuracy. However, the time margin from the forecast completed to the actual time is small. 


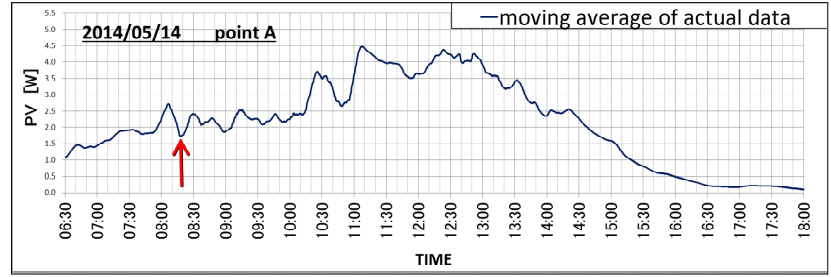

(a) Power Generation of $\mathrm{PV}$ at point $\mathrm{A}$

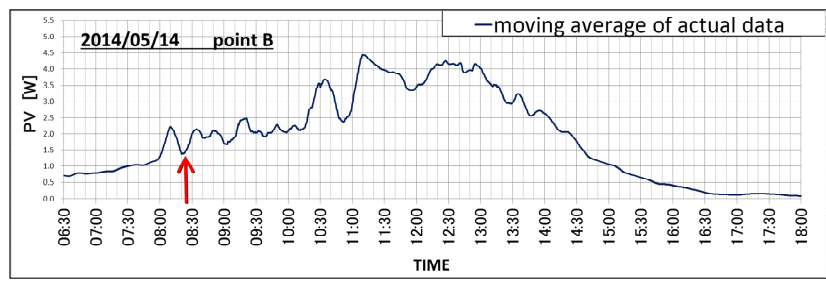

(a) Power Generation of PV at point $\mathrm{B}$

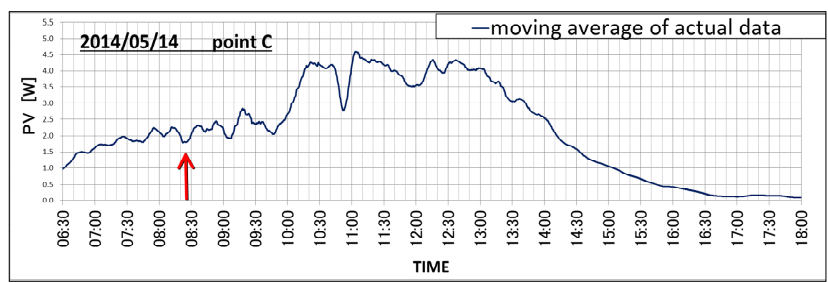

(c) Power Generation of $\mathrm{PV}$ at point $\mathrm{C}$

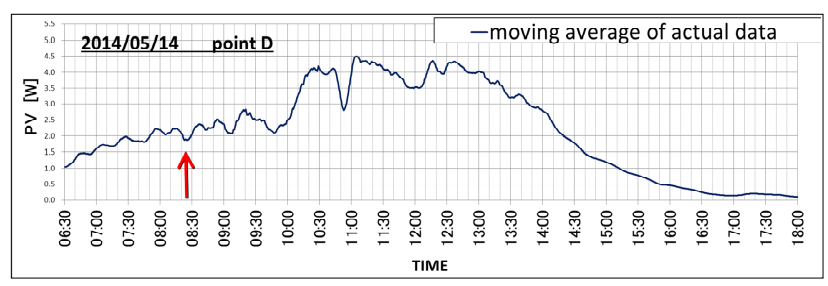

(d) Power Generation of $\mathrm{PV}$ at point $\mathrm{D}$

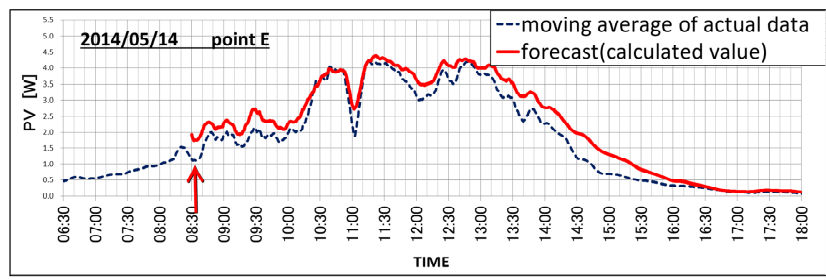

(e) Power Generation of $\mathrm{PV}$ at point $\mathrm{E}$ (actual data and forecasted data)

Fig. 5. Forecast of Power generation using four point data.

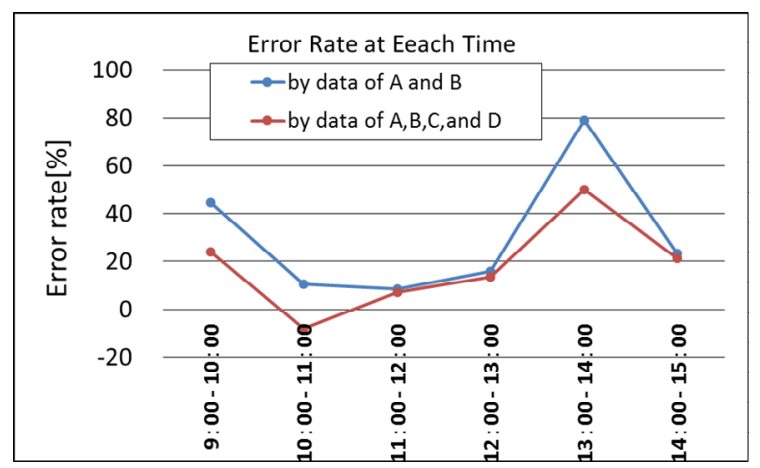

Fig. 6. Error Rate.

\section{Application for Voltage Assessment of Distribution Network}

\section{A. Simulation}

The resulting solar radiation forecast data are applied to voltage control of a distribution network [26]. For this study, five nodes are placed in the distribution system. Then voltage analysis by simulating the power distribution line is performed based on demand and PV generation. Generally in Japan, three-phase $6,600 \mathrm{~V}$ is supplied to each node over lines extending several kilometers. The voltage is changed to $200 \mathrm{~V} / 100 \mathrm{~V}$ by pole transformers. The simulation model has a distribution line with total length of $5 \mathrm{~km}$. It is assumed that each of the five nodes supplies customers with up to $600 \mathrm{~kW}$ and that each is connected to PV rated as $400 \mathrm{~kW}$. For the PV output at each node and for sending end voltage at the substation, a power flow calculation is performed at a fixed time interval. The sending end voltage at the substation is increased or decreased according to the power supplied from the substation. Furthermore, PV output forecast values are also considered in calculations. In Japan, voltage must be maintained within the range of 95-107 V by law. Each node voltage of the distribution line is calculated for the time intervals based on sending end voltage conditions. Fig. 7 shows the model used for the simulation. Table 2 presents conditions of the simulation.

Table 1. RMSE and Time Margin of Forecasting

\begin{tabular}{|c|c|c|}
\hline $\begin{array}{c}\text { Number of } \\
\text { measuring } \\
\text { points }\end{array}$ & $\begin{array}{c}\text { Root Mean Squared } \\
\text { Error (RMSE) }\end{array}$ & Time margin \\
\hline Two points & 13.20 & $15 \mathrm{~min}$ \\
\hline Four points & 11.63 & $9 \mathrm{~min}$ \\
\hline
\end{tabular}

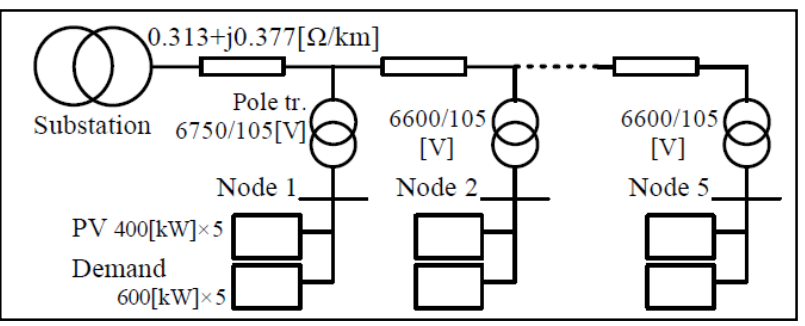

Fig. 7. Simulation Model for Distribution Network.

Table 2. Simulation Conditions

\begin{tabular}{|l|l|}
\hline Number of nodes & 5 \\
\hline Demand power & $600 \mathrm{~kW} /$ node (fixed value) \\
\hline PV generation & $400 \mathrm{~kW} /$ node (time series value) \\
\hline $\begin{array}{l}\text { Time zone for } \\
\text { simulation }\end{array}$ & $6 \mathrm{hr}(9: 00-15: 00$, every 10 s) \\
\hline Input data (PV) & 2160 values/node \\
\hline Input data (demand) & 2160 values/node (fixed value) \\
\hline $\begin{array}{l}\text { Substation output } \\
\text { voltage }\end{array}$ & $\begin{array}{l}6550,6500,6450,6400,6350, \\
6300,6250,6200[\mathrm{~V}]\end{array}$ \\
\hline Output data & $\begin{array}{l}2160 \text { values } \\
\text { (voltage value of 100 V line) }\end{array}$ \\
\hline
\end{tabular}




\section{B. Numerical Results}

Forecast results are used to assess voltage at five nodes. After fixing the sending end voltage based on the power supplied by the substation transformer, many time series of PV output data are prepared. These time series data correspond to the PV output forecast. Although the PV output varies, the sending end voltage is fixed, so voltage deviation from the permissible range might occur. For simplicity, the PV output forecast is assumed here to be accurate. Fig. 8 presents an application example for May 8 , 2014, representing the voltage at Node 5. For comparison, a fixed voltage case irrespective of supply power from a distribution transformer is studied as Case (a). Case (b) employs sending end voltage control as described earlier. No voltage violation occurs in the case of the sending end voltage control, although a large probability of voltage violation occurs in the fixed voltage case.
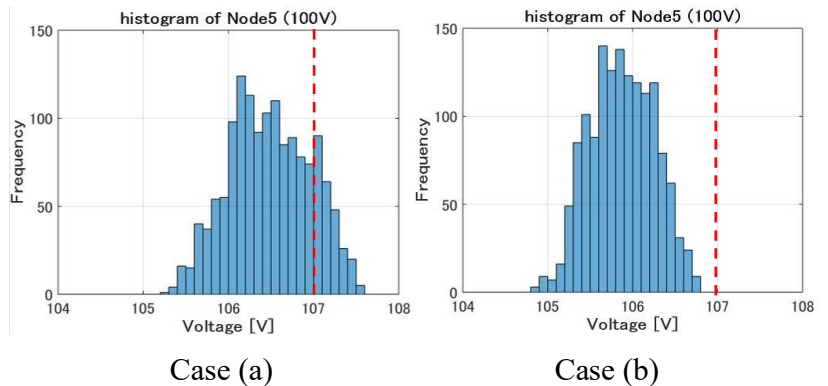

Fig. 8. Frequency distribution of Voltage at Node 5.

\section{Conclusion}

As described in this paper, a novel voltage control method is proposed using a short-term forecast of PV output. The sending end voltage control by tap changing at the distribution substation based on the forecast data has been proven to be effective. Results show that the voltage is maintained in the power distribution system within a specified value using these methods. Furthermore, the disconnection frequency of the PCS can be decreased. Future studies should assess the risks of forecast error using probabilistic analysis.

\section{Acknowledgment}

The author thanks Professor Yasuhiro Noro of Kogakuin University who cooperated in collecting data.

\section{References}

[1] D. Díaz, J.A. Souto, A. Rodríguez, S. Saavedra, J.J. Casares, A. García-Loureiro, R. Varela, M.J. Rodríguez-Legarreta, J. and Rodríguez-Aneiros "Controlled power distributed photovoltaic system using solar energy forecast", in Proceedings of the International Conference on Renewable Energies and Power Quality (ICREPQ'12), Santiago de Compostela (Spain), 2012, 5, pp. $350-354$

[2] E. Lorenz, J. Remund, S.C. Müller, W. Traunmüller, G. Steinmaurer, D. Pozo, J.A. Ruiz-Arias, V. Lara, L. Ramírez, M. Gaston, C. Kurz, L.M. Pomares, and C. Geijo. "Benchmarking of different approaches to forecast solar irradiance", in Proceedings of 24 European Photovoltaic and Solar Energy Conference and Exhibition, Hamburg 2009b, (Germany), pp. 10.
[3] K. Yasunami and T. Washio, "An Estimation Method of Cross-Correlation Function using Spatiotemporal Attenuation Model for Photovoltaic Generation Power Fluctuation Analysis", IEEJ Transactions on Power and Energy, Vol. 135, No. 10, pp. 613-623 (2015) (in Japanese)

[4] D. Díaz, J.A. Souto, A. Rodríguez, S. Saavedra, and J.J. Casares, "An ensemble-in-time forecast ofsolar irradiance" in Proceedings of the International Conference on Renewable Energies and Power Quality (ICREPQ'12), Santiago de Compostela (Spain), 2012, 5 pp. 3465-3485. (on-line at the Conferences series website)

[5] J.M. Botana, A. Rodríguez, and J.A. Gonzalez, "Testing new ensemble forecasts of solar irradiance" in Proceedings of the International Conference on Renewable Energies and Power Quality (ICREPQ'15), A Coruña (Spain), 2015, 5 pp. (on-line at the Conferences series website)

[6] Yoshio Yamagishi, Kensuke Saji, Isao Aoki, Ryoichi Tanikawa, and Yasumasa Fujii, "Accuracy Verification of Irradiance Forecast using Numerical Weather Prediction Data by Japan Meteorological Agency", IEEJ Trans. PE, Vol. 132, No. 4, pp. 334-340 (2012). (in Japanese)

[7] Takae Shimada and Kosuke Kurokawa, "Insolation

Forecasting Using Weather Forecast with Weather Change Patterns", IEEJ Trans. PE, Vol. 127, No. 11, pp. 1219-1225 (2007). (in Japanese)

[8] Fumitoshi Nomiyama, Takuma Murakami, Joji Asai, Hirotaka Takano, and Junichi Murata, "Day Ahead Global Solar Radiation Forecasting Using Binary Trees and Factor Analysis", IEEJ Transactions on Power and Energy, Vol. 134, No. 4, pp. 353-359 (2014)

[9] Takanobu Suzuki, Yusuke Goto, Takahiro Terazono, Shinji Wakao, and Takashi Oozeki, "Forecast Method of Solar Irradiance with Just-In-Time Modeling”, IEEJ Trans. PE, Vol. 131, No. 11, pp. 912-919 (2011). (in Japanese)

[10] Hideaki Ohtake, Ken-obi Shimose, Joao Gari da Silva Fonseca Junior, Takumi Takashima, Takashi Oozeki, and Yoshinori Yamada, "Evaluation of Forecast Errors of the Global Solar Irradiance Obtained from the Japan Meteorological Agency Global Spectral Model", IEEJ Transactions on Power and Energy, Vol. 134, No. 6, pp. 501-509 (2014).

[11] Fujihiro Yamada, Yoshihiko Wazawa, Kazuhiro Kobayashi, Yasushi Miwa, Tomoki Kinno, Kazuto Yukita, Yasuyuki Goto, and Katsuhiro Ichiyanagi, "Prediction of Next Day Solar Power Generation by Gray Theory and Neural Networks", IEEJ Transactions on Power and Energy, Vol. 134, No. 6, pp. 494-500 (2014).

[12] Hisatomo Miyata, Kazutoshi Miyashita, Takayuki Endo, Yuichi Shimasaki, Tatsuya Iizaka, and Toru Katsuno "A Study of a Next Day Electric Load Curve Forecasting Method and its Accuracy Improvement", IEEJ Transactions on Power and Energy, Vol. 134, No. 1, pp. 9-15 (2014).

[13] R. Perez, S. Kivalov, J. Schlemmer, K. Hemker, D. Renné, and T.E. Hoff, "Validation of short and medium term operational solar radiation forecasts in the US", Sol. Energy, Vol. 84, pp. 2161-2173, (2010).

[14] Yoshio Yamagishi and Yasumasa Fujii, "Accuracy Verification of Arbitrary Point Insolation Estimation using the Automated Meteorological Data Acquisition System Data", IEEJ Trans. PE, Vol. 132, No. 1, pp. 65-70 (2012). (in Japanese) [15] Motoki Akatsuka, Ryoichi Hara, Hiroyuki Ita, Tomoyuki Fukushima, Atsushi Sakahara, and Takatoshi Matsumoto, "Generation of Time Series of Spatially Averaged Solar Radiation in $10 \mathrm{~km}$ Square Are based on Solar Radiation at Single Location and Evaluation by Occurrence Frequency of Fluctuation Range", IEEJ Transactions on Power and Energy, Vol. 134, No. 4, pp. 311-319 (2014).

[16] Toshiya Nanahara, Katsuhisa Yoshimoto, Eitaro Omine, Shin-obi Nishino, and Yoshihiko Wazawa, "Correlation in Short-Term Fluctuations of Solar Irradiances across an Area Analysis of Correlation on a Day with Large Fluctuations -", 
IEEJ Transactions on Power and Energy, Vol. 134, No. 4, pp. 336-343 (2014).

[17] Takeyoshi Kato and Yasuo Suzuki, "A Study of Estimation of Average Power Output Fluctuation of Clustered Photovoltaic Power Generation Systems in Urban District of a few km2," IEEJ Trans. PE, Vol. 130, No. 2, pp. 214-222, (2010) (in Japanese).

[18] Kazuhiro Hidaka, Yukio Shinoda, and Tomoki Okamoto, "A Study of Wide Area Output Estimation of Photovoltaic Systems", IEEJ Transactions on Power and Energy, Vol. 134 No. 6, pp. 477-483 (2014).

[19]. Hiroyuki Nagoya, Shintaro Komami, Kazuhiko Ogimoto, and Yumiko Iwafime, "A Study for Impact of Parameter Identification on Presumed Total Output of Highly Penetrated Photovoltaic Generation Fluctuation Considering Mutual Smoothing Effect", IEEJ Transactions on Power and Energy, Vol. 134, No. 4, pp. 296-303 (2014).

[20] Yoshihiko Kataoka, “An Observability Index for Evaluation of Measurement Formation in Estimation of the Total Output of Widely Distributed Solar Photovoltaic Generators", IEEJ

Transactions on Power and Energy, Vol. 134, No. 4, pp. 320-327 (2014).

[21] Mitsuru Kudo, Akira Takeuchi, Yousuke Nozaki, Hisahito Endo, and Jiro Sumita, "Forecasting Electric Power Generation of Photovoltaic Power System for Energy Network", IEEJ Trans. PE, Vol. 127, No. 7, pp. 847-853 (2007). (in Japanese)

[22] Ricardo Marquez and Carlos F.M. Coimbra, "Intra-hour

DNI forecasting based on cloud tracking image analysis", Solar Energy, Vol. 91, No. 327-336 (2013)

[23] Y. Makino, M. Kurimoto, T. Kato, and Y. Suzuki,

"Nowcasting of Spatial Average Irradiance in Several kilometer Radius Area using All-sky Image", IEEJ Trans. PE, Vol. 134,

No. 6, pp. 510-517 (2014). (in Japanese)

[24] Ryuji Kawai, Katsuhiro Ichiyanagi, Kazuto

Yukita,Yasuyuki Goto, Kazuhiro Kobayashi, and Yasushi Miwa, "Forecasting of Short Period Variation due to Photovoltaic Power - Estimation of solar radiation using cloud image data of several points -," 2014 Annual Meeting Record IEEJ, Vol. 6, pp. 227-228. (in Japanese)

[25] H. Kobayashi and J. Arai, "Short-term Forecast for Photovoltaic Power Generation with Correlation of Solar Power Irradiance of Multi Points", Recent Researches in Electrical Engineering (WSEAS) pp. 89-94 (2014).

[26] J. Kondoh, "Evaluation on Reduction of Output Suppression Loss by Cooperative Control of Voltage Profile in a Distribution System with a Large Amount of Photovoltaic Power Generation Short-term Forecast for Photovoltaic Power Generation”, IEEJ Trans. PE, Vol. 130, No. 11, pp. 981-988

(2010). (in Japanese) 